\title{
Şirket Vakıfları: En Zengin 100 Türk Listesi Üzerine Keşifsel Bir Çalışma
}

\author{
DOI: 10.26466/opus.950607
}

\author{
$*$ \\ $\underline{\text { Üzeyir Yildız }}$ \\ * Araş. Gör. Dr., Yalova Üniversitesi, İktisadi ve İdari Bilimler Fakültesi, Yalova/Türkiye \\ E-Posta: uzeyir.yildiz@yalova.edu.tr ORCID: 0000-0002-8301-9975
}

\section{$\ddot{O} z$}

Son yillarda kurumsal sosyal sorumluluk ve kurumsal hayırseverlik konularl şirketlerin gündeminde yer alan önemli konular arasında yer almaktadır. Bu nedenle ilgili yazında kurumsal sosyal sorumluluk ve ilgili kavramlar farklı bağlamlarda araştırmacilar tarafindan sıklıkla ele alınıp incelenmektedir. Bu çalışmanın amacı Türkiye bağlamında tarihsel süreçte vakıf ve hayırseverlik kavramlarını detaylı bir şekilde tanıtmak ve Türkiye'nin en zengin ailelerinin sahip oldukları şirket gruplarının kurumsal sosyal sorumluluk faaliyetlerini gerçekleştirmek üzere kurdukları ve destekledikleri şirket vakıflarının görünümünü analiz etmektir. Çalışma nitel bir çalışma olup ikincil verilere ve şirket vakıflarına ilişkin demografik verilere dayanmaktadır. Türk iş sisteminde yer alan aile şirketlerini yansıtacak bir örneklem olarak Forbes Türkiye dergisinin her yıl yayınladı̆̆g "En Zengin 100 Türk" listesi kabul edilmiştir. 2020 yılına ait listedeki en zengin 100 kişiye ilişkin şirket vakıfları web siteleri yoluyla taranmış, ulaşılan 22 şirket vakfının kuruluş tarihleri ve ağırlıklı faaliyet alanları listelenmiştir. İlgili yazında Türkiye'de aile şirketlerinin kurmuş olduğu vakıflara ilişkin bir çalışma olmadığından bu çalışmanın daha sonraki çalışmalar için temel oluşturacă̆ı düşünülmektedir.

Anahtar Kelimeler: Kurumsal Sosyal Sorumluluk, Kurumsal Hayırseverlik, Şirket Vakıfları, Türkiye. 


\title{
Corporate Foundations: An Exploratory Study on the 100 Richest Turkish People List
}

\begin{abstract}
In recent years, the concept of corporate social responsibility and corporate philanthropy become one of the popular topics on the agenda of the companies. Therefore, corporate social responsibility has also received considerable attention in literature. The aim of this study is to reveal corporate philanthropic activities of Turkish business groups and to analyze the outlook of corporate foundations which were founded by richest families in Turkey. This study is a qualitative study based on the data collected through website of the corporate (sponsored) foundations. The sample of family businesses in Turkish for this investigation is gathered from "100 Richest People of Turkey in 2020" list published by the Forbes magazine. Firstly, the websites of holdings or business groups were investigated and the corporate foundations of Richest Families were examined and, secondly, the founding years and fields of activity of corporate foundations are also revealed. After investigation via internet websites, 22 corporate foundations are listed. According to findings, big majority of the corporate foundations has been founded in last thirty years. Since the study employed "Turkey's 100 Richest Family" list by Forbes magazine, this could cause to ignore some corporate foundations. There are no studies regarding corporate foundations in Turkey and their philantrophic activities in literature in details and therefore this study creates a base for further studies.
\end{abstract}

Keywords: Corporate Social Responsibility, Corporate Philanthropy, Corporate Foundations, Turkey. 


\section{Giriş}

Güncel tartışmalar içerisinde sürdürülebilir kalkınma için önemli uygulamalardan biri olarak kabul edilen kurumsal sosyal sorumluluk son yıllarda şirketlerin önem verdiği konular arasında yer almaktadır. Günümüzde kurumsal sosyal sorumluluk, şirketlerin sadece ürün ve hizmet üretmekle kalmayıp, içinde bulundukları toplumun sorunlarına yönelik projeler üretmeleri, bu amaçla gerçekleştirilen faaliyetlere destek vermeleri şeklinde kabul görmektedir. Bu anlamda toplumların işletmelerden beklentileri ve istekleri artmakta ve artık işletmeler sadece ekonomik faaliyetleriyle değil, ayrıca topluma karşı yerine getirmesi gereken diğer sosyal sorumlulukları yönüyle de değerlendirilmektedir. Bu bağlamda bu çalişmada öncelikle Türkiye'de şirketlerin kurumsal sosyal sorumluluk uygulamalarının temelini oluşturan hayırseverlik kavramı kavramsal açıdan ve farklı yönleriyle ele alınarak incelenmektedir. Ayrıca Türkiye'de kurumsal sosyal sorumluluk faaliyetlerinin tarihsel süreç içerisindeki gelişimi üzerinde durulmakta ve Türk iş sisteminde şirket vakıfları listesi ve faaliyet alanları ortaya konularak şirket vakıflarıns ilişkin daha sonra yapılacak çalışmalar için bir temel ortaya koymak amaçlanmaktadır.

\section{Kurumsal Sosyal Sorumluluk Kavramı ve Uygulamaları}

Günümüzde kurumsal sosyal sorumluluk ve kurumsal hayırseverlik konuları araştırmacılar tarafından sıklıkla ele alınan ve araştırılan konular arasındadır. Bu kavramlar ilk ortaya çıktıktan bugüne dek önemli değişiklikler ve dönüşümler geçirmiştir (Carroll, 1979:497). İlk başlarda işletmelerin sosyal sorumluluk faaliyetleri adına "kâr ediyor olmak" yeterli bir ölçüt iken, 2000'li yıllarda şirketlerden sosyal sorumluluk bağlamında ekonomik sorumluluklarının yanında toplum için sosyal fayda yaratmaları da beklenmektedir (McWilliams vd.2001:117). Yaşanan bu dönüşüm kurumsal sosyal sorumluluk uygulamalarına verilen önemin artmasına da sebep olmuştur. Kurumsal sosyal sorumlulukla ilgili literatüre bakıld1ğında, bu kavramın tanımı üzerinde tam bir uzlaşmanın olmadığı ve bu kavramla ilgili çok farklı tanımlamaların olduğu görülmektedir (Bowen,

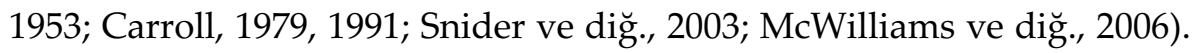
McWilliams ve diğerleri (2006) kurumsal sosyal sorumluluğu "firmanın 
uyumun ötesine geçtiği ve 'firmanın çıarlarının ve yasaların gerektirdiğinin ötesinde bazı sosyal yararları ilerletiyor gibi görünen eylemlerde bulunduğu durumlar'" olarak tanımlamaktadır (McWilliams ve diğ., 2006:1). Mohr ve diğerleri (2001) ise kurumsal sosyal sorumluluğu, şirketin toplum üzerindeki her zararlı etkiyi en aza indireceği veya ortadan kaldıracağı ve uzun vadeli faydaları azami dereceye çıkaracağının taahhüdü olarak açıklamaktadır. Bu konuyla ilgili olarak Avrupa Komisyonu tarafından yayımlanan Yeşil Kitap, şirketlerin KSS uygulamalarını günlük operasyonlarına ve paydaşlarıyla olan etkileşimlerine bütünleştirmeleri gerektiğine işaret etmektedir (Yeşil Kitap, 2001). KSS'nin bu tanımlarını yeterli bulmayan Aktan (2007) ise kurumsal sosyal sorumluluk kavraminı "herhangi bir örgütün hem iç hem de dış çevresindeki tüm paydaşlara karşı "etik" ve "sorumlu" davranması, bu yönde kararlar alması ve uygulaması şeklinde" tanımlamaktadır.

Konu ile ilgili uluslararası literatüre baktığımızda şirketlerin yerine getirmesi gerektiği sorumlulukların sınırları ile ilgili olarak farklı bakış açılarının olduğu görülmektedir. Friedman (1962) gibi bazı yazarlar ise şirketlerin kar sağlama amaçlarının ötesinde başka bir sorumluluğunun olmadığını ifade etmekte ve Kapitalizm ve Özgürlük adlı kitabında ise "Şirket, ona sahip olan hissedarların aracıdır. Şirket bağış yaparsa, hissedarların kaynaklarını nasıl kullanacağına bireysel olarak karar vermelerini engeller" diyerek şirketlerin bağış yapmalarına karşı çıkmaktadır. Robins (2005) gibi bazı araştırmacılar ise şirketlerin gerçekleştirmiş oldukları faaliyetlerinde ekonomik olmayan ama toplumu ve doğayı etkileyen sonuçların farkında olması ve bu konularda sorumluluk almaları gerektiğini ifade etmektedirler.

Literatürde KSS'nin boyutları ile ilgili olarak en çok kabul gören model, Carroll (1991)'un ekonomik, yasal, etik ve hayırseverlik sorumluluklarından oluşan dört boyutlu kurumsal sosyal sorumluluk piramididir. Carroll'a göre işletmeler, bu sorumluluklarını eşzamanlı olarak yerine getirmelidirler. İşletmelerin ekonomik sorumlulukları piramidin en alt bölümünde yer almakta ve diğer sorumlulukların da temel dayanağını oluşturmaktadır. Yasal sorumluluklar ise toplumun işletmelerden kabul edilebilir ve kabul edilemez davranışları, kodları olan yasalara uymalarını ifade etmektedir. Daha sonra ise işletmelerin ahlaki sorumlulukları gereği 
doğru, adil ve vicdani olanı yerine getirmeleri ve kötülük yapmaktan kaçınmaları beklenmektedir (Carroll, 1991, s.41-45). Hayırseverlik boyutu Carroll'un KSS piramidi'nin en üst bölgesinde yer almaktadır. KSS'nin bu boyutunda amaç iyi bir kurumsal vatandaş olarak toplum için yararlı faaliyetlere katkıda bulunmak ve içinde yer aldığ 1 toplumun yaşam kalitesini iyileştirmeye dönük çalışmalar yapmaktır.

Kurumsal hayırseverlik, şirketlerin iyi bir kurumsal vatandaş olarak toplumun beklentilerini yerine getirmek için gerçekleştirdiği tüm kurumsal faaliyetleri kapsamaktadır. Bu toplumun refahını arttıran ve destekleyen tüm sanatsal programları da aktif olarak içermektedir. Bununla birlikte hayırseverlik ile etik sorumluluklarını birbirinden ayıran temel özellik, etik sorumluluğa karşın hayırseverliğin etik ve ahlak duygusu içerisinde toplum tarafından beklenilmediğidir. Toplumlar, şirketlerden insani program ve amaçlar için para yardımı yapmalarını, sahip olduğu imkanları seferber etmelerini ve çalışanlarının zamanlarından da katkılar sunmalarını arzu ederler. Ancak toplum tarafından arzu edilen bu sorumlulukları yerine getirmeyen şirketlere ahlaki değerlerden ya da etikten yoksun olarak bakılmaz (Caroll, 1991, s.42).

Kurumsal hayırseverlik ve etkileri ile ilgili yukarıdaki açıklamaların yanı sıra literatürde farklı bakış açıları da bulunmaktadır (Porter ve Kramer, 1999; Simon, 1995). Örneğin Porter ve Kramer (1999), “Hayırseverliğin Yeni Gündemi: Değer Yaratmak" adlı makalesinde, hayır kurumlarının toplumsal değer yaratabileceği dört yolu şu şekilde tanımlamaktadır: en iyi bağış alıcıları seçmek, diğer fon sağlayıcıların dikkatini çekmek, bağış alıcıların performansını geliştirmek ve alandaki bilgi ve uygulamayı ilerletmek. Yazarlara göre aynı ilkeler kurumsal hayırseverlik için de geçerlidir. Bu dört ilkeye odaklanılması, kurumsal bağışların ve hayırseverliğin aynı miktardaki bireysel bağışlardan daha büyük etki yaratmasını da sağlamaktadır. Şirketler, hayırseverlik çabalarını, faaliyet gösterdikleri coğrafi bölgelerde iş ortamının kalitesini geliştirmek için kullanabilirler ve böylece toplumsal ve ekonomik hedefler arasında uyum yaratılmasını sağlarlar. Bunun sonucunda da şirketlerinin uzun vadeli iş beklentilerini de geliştirirler. Ayrıca bağlama odaklanılması, bir şirketin sadece hayırsever amaçları desteklemek için para vermesini değil, bu çaba içinde kendi yetkinliklerini ve ilişkilerini sağlamlaştırmasına da imkân verecektir (Porter ve Kramer, 2002). 
Bu bağlamda birçok uluslararası şirketin kurumsal hayırseverliği, stratejik bakış açısıyla tekrar tanımlayarak şirket stratejileri ile bütünleştirmeye çalıştıkları görülmektedir. Stratejik hayırseverlik, şirkete sağlayacağı kısa dönemli faydalardan ziyade, şirketin uzun dönemli rekabet gücünü artıracak bir unsur olarak görülmektedir (Simon, 1995, s.20). Stratejik hayırseverlik uygulamasını başlatan ilk işletme Amerika'da AT\&T olmuştur. AT\&T tarafından kurulan vakfın başkanlığını yapan Reynold Levy'nin vakıf faaliyetlerinin şirket amaçlarıyla bağlantısını kuran düşünceleri, hayırseverlik faaliyetlerine stratejik olarak yaklaşmaya öncülük etmiştir (McAlister ve Ferrell, 2002, s.689). Ancak Porter ve Kramer (2002)'e göre bugünkü stratejik hayırseverlik faaliyetleri hiç de sanıldığı kadar stratejik değildir. Yazarlara göre hayırseverlik giderek amaca yönelik pazarlama ya da diğer üst düzey sponsorluklar aracılığıyla bir şirketin imajını ya da markasını tanıtmak için bir halkla ilişkiler ya da reklamcılık yöntemi olarak kullanılmaktadır. Ancak amaca yönelik pazarlama, toplumsal etkiyi değil, tanıtımı vurgular. Onlara göre gerçek anlamda stratejik bağış ya da hayırseverlik faaliyetleri, ekonomik amaçlarla birlikte önemli toplumsal amaçlara aynı anda yönelerek, şirketin özgün varlıklar ve uzmanlık geliştirmesi nedeniyle hem toplumun hem de şirketin fayda sağladığı rekabetçi alanlarını hedefler. Bu gelinen noktada özellikle batı kaynaklı iş dünyasında hayırseverliğin stratejik bir araç olarak görüldüğü ve kullanıldığı anlaşılmaktadır.

\section{Tarihsel Boylamda Türkiye'de Hayırseverlik Faaliyetleri}

Türkiye' de hayırseverlik denilince ilk olarak akla Osmanlı döneminde hayırseverlik faaliyetlerini yürüten vakıflar gelmektedir. Osmanlı döneminde vakıflar, toplumun gelişmesine hizmet eden en önemli hayırseverlik kurumlarıdır. Çünkü başta sağlık ve eğitim olmak üzere birçok hizmetler bu vakıflar sistemi sayesinde yerine getirilmiştir. Tarih boyunca okullar, üniversiteler, hastaneler, aşevleri, köprüler, yollar, limanlar, kütüphaneler, çeşmeler ve ekonomik kalkınmaya katkıda bulunan sayısız başka hizmetler vakıflar tarafından gerçekleştirilmiştir (Çizakça, 2006, s.21).

Vakıfların işleyiş̧ine bakıldığında bağış, gelir ve amaç olmak üzere üç ana unsur göze çarpmaktadır. Zengin bir birey sağlık, eğitim ve diğer alanlarda zorunlu bir ihtiyaç gördüğü zaman, bu sorunu çözmek üzere bir 
vakıf kurmuştur. İslam dinine göre topluma yararlı işler yapmanın kişiye öldükten sonra dahi sevap kazandırıyor olması, Osmanlı' da zengin insanların vakıflar kurmalarında en önemli motivasyon kaynağı olmuştur (Çizakça, 2006: 23). Bununla birlikte Osmanlı Devleti'nin gerileme dönemlerinde özellikle de 19. yüzyılın ikinci yarısından itibaren vakıflar misyonlarını yerine getiremez hale gelmişlerdir. $\mathrm{Bu}$ gerilemenin sonucu olarak Cumhuriyet hükümetleri, çok geniş bir coğrafi alana yayılmış ancak gelirleri giderlerini karşılamayan, ağır yönetim sorunları içinde bulunan, zengin kültür ve tarihsel birikime sahip bir vakıf düzenini Osmanlı' dan devralmıştır (Aydın, 2006, s.35-36).

\section{Türk İş Sistemi'nde Şirket Vakıfları}

Osmanlı'daki vakıf sistemi temelinde gelişen hayırseverlik faaliyetlerinin Türkiye Cumhuriyeti döneminde iş sistemi içerisinde sürdürüldügü görülmektedir. 1960'lı yıllardan sonra iş adamları sosyal sorunların çözümüne katkıda bulunmak amacıyla yapmış oldukları çalışma ve kurumsal hayırseverlik faaliyetlerini kurumsal bir yapı altında gerçekleştirmek için kendi aile vakıflarını kurmaya başlamışlar ve vakıf sistemini tekrar canlandırmışlardır. Osmanlı'da olduğu gibi özellikle zengin aileler tarafından kurulan bu aile vakıfları da genel olarak eğitim, sağlık, kültür ve sanat gibi alanlarda faaliyetlerini yürütmektedir. Bu doğrultuda ilgili vakıflar Türkiye'nin daha hızlı gelişmesine destek olduğu ve toplumsal sorunların çözümüne katkılar sunmaktadırlar.

Bu çalışma, Türk iş sistemi içerisinde kurulan şirket vakıflarına ilişkin ikincil verilere ve demografik verilere dayalı nitel bir çalışmadır. Araştırma kapsamında öncelikle Türk iş sisteminde yer alan şirket vakıflarını yansıtabilecek bir örnekleme ulaşmak için kriter alınacak bir liste araştırılmış ve büyük aile işletmeleri ya da holdingleri kapsayacak en uygun liste olarak Forbes dergisinin her yıl yayınladığı "Türkiye'nin En Zengin 100 Türk" listesi uygun bir liste olarak kabul edilmiştir. 2020 yılına ait listenin elde edilmesiyle 100 zengin kişiye ilişkin holding ve aile vakıfları internet yoluyla taranmış, vakıfların kuruluş yılları ve ağırlıklı faaliyet alanları temelinde bir liste hazırlanmıştır. Araştırma' da "Türkiye'nin En Zengin 100 Türk" listesi üzerinde çalışma yapılması elbette bazı şirket vakıflarının göz ardı edilmesine sebep olabilir. Ancak mevcut literatürde şirket vakıflarına 
Tablo 1. Türk İş Sisteminde Şirket Vakıfları

\begin{tabular}{|c|c|c|c|c|}
\hline Kurucu Aile & Holding Adı & Vakıf Adı & Faaliyet Alanı & $\begin{array}{l}\text { Kuruluş } \\
\text { Yilı }\end{array}$ \\
\hline Koç Ailesi & Koç Holding & Vehbi Koç Vakfı & Eğitim, Sağlık ve Kültür & 1969 \\
\hline Sabancı Ailesi & Sabancı Holding & $\begin{array}{l}\text { Hacı Ömer Sabancı } \\
\text { Vakfı }\end{array}$ & Kültür, Sosyal ve Eğitim & 1974 \\
\hline Eczacıbaşı Ailesi & $\begin{array}{l}\text { Eczacıbaşı Hol- } \\
\text { ding }\end{array}$ & $\begin{array}{l}\text { Eczacıbaşı Vakfı } \\
\text { (Dr. Nejat F. Ecza- } \\
\underline{\text { cıbaș Vakfı) }}\end{array}$ & $\begin{array}{l}\text { Araştırma, Kültür ve Sa- } \\
\text { nat }\end{array}$ & 1978 \\
\hline $\begin{array}{l}\text { Yazıcı Ailesi } \\
\text { Özilhan Ailesi }\end{array}$ & $\begin{array}{l}\text { Anadolu Grubu } \\
\text { Holding }\end{array}$ & Anadolu Vakfı & Sağlık, Eğitim ve Sosyal & 1979 \\
\hline $\begin{array}{l}\text { Tara Ailesi } \\
\text { Gülçelik Ailesi }\end{array}$ & Enka Holding & Enka Vakfı & Spor, Eğitim ve Sosyal & 1983 \\
\hline Hüsnü Özyeğin & Fiba Holding & $\begin{array}{l}\text { Hüsnü M. Özyeğin } \\
\text { Vakfı }\end{array}$ & Kültür, Eğitim ve Sağlık & 1990 \\
\hline $\begin{array}{l}\text { Ferit Şahenk } \\
\text { Filiz Şahenk }\end{array}$ & Doğuş Holding & $\begin{array}{l}\text { Ayhan Şahenk } \\
\text { Vakfı }\end{array}$ & Eğitim, Kültür ve Sanat, & 1992 \\
\hline Doğan Ailesi & Doğan Holding & $\begin{array}{l}\text { Aydın Doğan } \\
\text { Vakfı }\end{array}$ & Eğitim ve Sağlık & 1996 \\
\hline Çarmıklı Ailesi & Nurol Holding & $\begin{array}{l}\text { Nurol Eğitim Kül- } \\
\text { tür ve Spor Vakfı }\end{array}$ & Eğitim, Kültür ve Spor & 1996 \\
\hline Zorlu Ailesi & Zorlu Holding & $\begin{array}{l}\text { Mehmet Zorlu } \\
\text { Vakfı }\end{array}$ & Eğitim, Sağlık ve Kültür & 1999 \\
\hline Kibar Ailesi & Kibar Holding & $\begin{array}{l}\text { Kibar Eğitim ve } \\
\text { Sosyal Yardım } \\
\text { Vakfı }\end{array}$ & Eğitim, Sağlık ve Sosyal & 1999 \\
\hline Hamdi Akın & Akfen Holding & $\begin{array}{l}\text { Türkiye İnsan Kay- } \\
\text { nakları Eğitim ve } \\
\text { Sağlık Vakfı }\end{array}$ & Eğitim, Sağlık ve Sosyal & 1999 \\
\hline $\begin{array}{l}\text { Mehmet Ali Ay- } \\
\text { dınlar }\end{array}$ & $\begin{array}{l}\text { Acrbadem Hol- } \\
\text { ding }\end{array}$ & $\begin{array}{l}\text { Acıbadem Sağlık } \\
\text { ve Eğitim Vakfı }\end{array}$ & Eğitim ve Sağlık & 2002 \\
\hline İnan Kıraç & Kıraça Holding & $\begin{array}{l}\text { Suna ve İnan Kıraç } \\
\text { Vakfı }\end{array}$ & Eğitim, Sağlık ve Kültür & 2003 \\
\hline İbrahim Çeçen & IC Holding & $\begin{array}{l}\text { İbrahim Çeçen } \\
\text { Vakfı }\end{array}$ & Eğitim, Kültür ve Sanat & 2004 \\
\hline Yalçın Sabancı & Yasa Holding & $\begin{array}{l}\text { Yalçın Sabancı Eği- } \\
\text { tim Vakfı }\end{array}$ & Eğitim & 2004 \\
\hline $\begin{array}{l}\text { Ülker Ailesi } \\
\text { Özokur Ailesi }\end{array}$ & Ylldız Holding & $\begin{array}{l}\text { Sabri Ülker Gıda } \\
\text { Araştırmaları Ens- } \\
\text { titüsü Vakfı }\end{array}$ & Sağlik & 2009 \\
\hline $\begin{array}{l}\text { Erdemoğlu Ai- } \\
\text { lesi }\end{array}$ & $\begin{array}{l}\text { Erdemoğlu Hol- } \\
\text { ding }\end{array}$ & $\begin{array}{l}\text { Mehmet Erde- } \\
\text { moğlu Vakfı }\end{array}$ & Eğitim, Sağlık ve Sosyal & 2009 \\
\hline Erman Ilıcak & $\begin{array}{l}\text { Rönesans Hol- } \\
\text { ding }\end{array}$ & $\begin{array}{l}\text { Rönesans Eğitim } \\
\text { Vakfı }\end{array}$ & Eğitim ve Sosyal & 2009 \\
\hline Ahmet Cengiz & Cengiz Holding & $\begin{array}{l}\text { Şaban Cengiz } \\
\text { Vakfı }\end{array}$ & $\begin{array}{l}\text { Eğitim, Spor, Sağllk ve } \\
\text { Kültür }\end{array}$ & 2013 \\
\hline Murat Varg1 & MV Holding & $\begin{array}{l}\text { Çöpüne Sahip Çık } \\
\text { Vakfı }\end{array}$ & Çevre & 2015 \\
\hline $\begin{array}{l}\text { Nihat Özdemir } \\
\text { Sezai Bacaksız }\end{array}$ & Limak Holding & $\begin{array}{l}\text { Limak Eğitim Kül- } \\
\text { tür ve Sağlık Vakfı }\end{array}$ & Eğitim, Kültür ve Sağlık & 2016 \\
\hline
\end{tabular}


ilişkin başka bir tasnife rastlanılmadığından ve listede yer alan nitelikteki ailelerin Türkiye'deki şirket vakıflarına ilişkin yapıyı yansıtabileceği düşünüldügünden bu yaklaşımın doğru bir tercih olabileceği kabul edilmiştir.

Türk iş sistemini temsil edecek bir örneklemde yapılan araştırma sonucunda toplamda 22 şirket vakfı tespit edilmiştir (Tablo 1).

Tablo 1'de de görüldüğü gibi örneklem doğrultusunda elde edilen verilere dayalı olarak ilk şirket vakfının 1969'da kurulduğu, 1990'larla birlikte hızlı bir artışa geçtiği ve 2000'lerde gelişimini sürdürdüğü anlaşılmaktadır. Listeye giren 22 şirket vakfından 18'nin 1980 sonrası dönemde kurulmuş olması liberal dönemle birlikte zengin ailelerin artması sonucu vakıf kurabilecek nitelikte holding sayısının çoğalmış olmasını akla getirmektedir.

Ayrıca listede yer alan 22 şirket vakfından 11'inin Gelir İdaresi Başkanlığı'nın resmî sitesinde yayımlanan bakanlar kurulu kararı ile vergi muafiyeti tanınan vakıflar listesinde yer alırken, diğer 8 'inin ise vergi muafiyeti tanınan vakıflar listesinde yer almadı̆̆ görülmektedir. Aile şirketleri listesinde yer alan 22 vakıftan 11 şirket vakfının vergi muafiyetine sahip olması, şirketlerin kendi vakıflarını kurmalarında vergi muafiyetinin de vakıf kurmada bir etken olabileceğini düşündürmektedir.

Aile vakıflarına ait web sitelerinin analizi 6 kategoride (eğitim-araştırma, kültür-sanat, sağlık, spor, çevre ve sosyal) nitel içerik analizine göre yapılmıştır (Tablo 2). Verilerin analizi için Hill (1994) aşağıdaki adımları takip edilmiştir: Illk olarak web siteleri tarandı. İkinci olarak, elde edilen bilgiler sıralandı ve ardından kategorilere ayrıldı. Üçüncüsü, bilgilerdeki benzerlikler belirlendi.

Çalışmanın sonuçları, şirket vakıflarının en öncelikli faaliyet alanının eğitim alanı olduğunu ve 22 şirket vakfından 21'inin eğitim alanına ilişkin faaliyetlere yer verdiklerini göstermektedir. Şirket vakıflarının öncelikli faaliyet alanları arasında eğitim-araştırma'da sonra en fazla önem verdikleri faaliyet alanları ise sağlık (\%59) ve kültür (\%50) olduğu görülmektedir. Ayrıca sayıları çok az da olsa bazı şirket vakıflarının dikkatlerini ve kurumsal sosyal sorumluluk çabalarını sağlık ve çevre gibi sadece belirli bir alanlarda yoğunlaştırdığı anlaşılmaktadır. 
Tablo 2. Türk İş Sisteminde Şirket Vakıflarının Faaliyet Alanları

\begin{tabular}{|c|c|}
\hline Faaliyet Alanları & Faaliyet Alanlarına İlişkin Örnek Projeler \\
\hline Eğitim\&Araştırma & $\begin{array}{ll}\bullet & \text { Üniversiteler } \\
\bullet & \text { Fakülteler } \\
\bullet & \text { Okullar } \\
\bullet & \text { Yurtlar } \\
\bullet & \text { Kütüphaneler } \\
\bullet & \text { Burslar } \\
\bullet & \text { Kitap Bağışlama } \\
\bullet & \text { Bilgisayar ve benzeri teçhizat Bağışlama }\end{array}$ \\
\hline Kültür\&Sanat & $\begin{array}{ll}\text { - } & \text { Kültür Merkezleri } \\
\text { - } & \text { Müzeler } \\
\text { - } & \text { Festivaller } \\
\text { - } & \text { Yarışmalar } \\
\text { - } & \text { Kültür ve Sanat Etkinlikleri } \\
\text { - } & \text { Sanat Galerisi } \\
\text { - } & \text { Sanat Koleksiyonları } \\
& \text { Sanat Ödülleri }\end{array}$ \\
\hline Sağlık & $\begin{array}{ll}\text { - } & \text { Hastaneler } \\
\text { - } & \text { Sağlık Merkezleri } \\
\text { - } & \text { Sağlıklı Gıda Araştırması } \\
\text { - } & \text { Sağlık Seminerleri } \\
\text { - } & \text { Tibbi malzeme }\end{array}$ \\
\hline Spor & $\begin{array}{ll}\text { - } & \text { Spor Tesisleri } \\
\text { - } & \text { Spor Kulüpleri } \\
\text { - } & \text { Spor Ödülleri } \\
\text { - } & \text { Spor Organizasyonları }\end{array}$ \\
\hline Çevre & $\begin{array}{ll}\text { - } & \text { Çevre Eğitimi } \\
\text { - } & \text { Çevre Farkındalığı Oluşturma } \\
\text { - } & \text { Ağaçlandırma } \\
\text { - } & \text { Atık Yönetimi } \\
\text { - } & \text { Yaban Hayatını Koruma }\end{array}$ \\
\hline Sosyal & $\begin{array}{ll}\text { - } & \text { Sosyal Tesisler } \\
\text { - } & \text { Sosyal Programlar } \\
\text { - } & \text { Kişisel ve Sosyal Gelişim } \\
\text { - } & \text { Çocuk Yuvası } \\
\text { - } & \text { Parklar } \\
\text { - } & \text { Sosyal Yardımlar } \\
\end{array}$ \\
\hline
\end{tabular}

\section{Sonuç ve Değerlendirme}

Literatürde kurumsal sosyal sorumluluk alanı içerisinde değerlendirilen kurumsal hayırseverlik faaliyetleri Türkiye bağlamında tarihsel süreçte canlı bir şekilde karşılık bulan bir olgudur. Osmanlı Devleti döneminde ağırlıklı olarak çok güçlü bir sistem olan vakıflar sistemi aracılığıyla işleyen hayırseverlik faaliyetlerinin Cumhuriyet döneminde holdingler tarafından kurulan yeni vakıflarla kurumsal sosyal sorumluluk faaliyetleri 
kapsamında devam ettirildiği görülmektedir. Özellikle Osmanlı'da büyük hizmetler vermiş vakıf sisteminin 21.yy'da Türk iş sistemi ve piyasa mekanizmasıyla stratejik bir biçimde şekillendirilmesi hem şirketler hem toplum açısından önemli bir katma değer yaratacaktır.

Osmanlı'da birçok hizmetin yerine getirildiği ve sosyal dokuyla uyumlu olan vakıf sisteminin 21.yy'da Türk iş sistemi ve piyasa mekanizmasıyla stratejik bir biçimde tekrar şekillendirilmesinin hem şirketler hem de toplum açısından önemli bir katma değer oluşturacağını söyleyebiliriz. Devletin aktif olduğu alanların giderek daraldığı günümüzde, vakıfların böylesi bir yaklaşımla ele alınmasının bir ihtiyacın ürünü olduğunu ve birçok alanda toplumun gelişimine önemli katkılar sağlayacağını söylemek mümkündür.

$\mathrm{Bu}$ çalışma her ne kadar Türkiye ve diğer örneklerdeki kurumsal hayırseverlik alanındaki farklı kurumsal mantıklara odaklanmasa da literatürde farklı bağlamlarda bu alanda farklı kurumsal mantıkların işlediğini akla getiren vurgular da mevcuttur. Bu bağlamda Türkiye'de Osmanlı'dan günümüze kadar gelen geleneksel hayırseverlik anlayışı ile Porter'ın önerdiği stratejik hayırseverlik yaklaşımlarının hangisinin daha baskın olduğu şirket vakıfları üzerine yapılacak çalışmalar ile ortaya konulabilecektir.

Türk iş sisteminde zengin ailelerin kurmuş oldukları şirket vakıflarına ilişkin bir ön çalışma niteliğinde olan bu çalışma, sınırlı bir örneklemde de olsa şirket vakıflarının Türk iş sisteminde azımsanmayacak bir oranda olduğunu ve 1960'lı yıllarını sonuna doğru kurulmaya başlanan vakıfların 1990'larda ivme kazandığını ve 2000'li yıllarda da bu trendin devam ettiğini göstermektedir. Ayrıca çalışmanın sonuçları, kurulan şirket vakıflarının ağırlıklı faaliyet alanları noktasında birbirinden etkilendiğini ve birçoğunun benzer faaliyet alanlarına ağırlık verdiğini göstermektedir.

Türk iş sisteminde şirket vakıflarına ilişkin yaşanan bu artış ve kurumsal sosyal sorumluluk faaliyetlerinin vakıflar aracılığıyla gerçekleştirilmesi anlayışı, Porter ve Kramer'in tavsiye ettiği stratejik hayırseverlik yaklaşımını Türkiye bağlamında analiz etmeye de imkân veren bir zemin oluşturmaktadır. Dolayısıyla bu çalı̧̧ma üzerine bina edilebilecek daha sonraki çalışmalarda şirket vakıfları ve faaliyet alanları üzerine daha derinlemesine odaklanılabilir ve vakıfların işleyişleriyle ilgili olarak farklı örneklemler üzerinden daha kapsamlı araştırmalar yapılabilir. 


\section{EXTENDED ABSTRACT}

\section{Corporate Foundations: An Exploratory Study on the 100 Richest Turkish People List \\ *}

Üzeyir Yildız

Yalova University

In recent years, the concept of corporate social responsibility and corporate philanthropy become one of the popular topics on the agenda of the companies. Therefore, corporate social responsibility has also received considerable attention in literature. The aim of this study is to reveal corporate philanthropic activities of Turkish business groups and to analyze the outlook of corporate foundations which were founded by richest families in Turkey.

Turkey has a rich and rooted history of "waqf or foundation and philanthropy (Ararat and Gocenoglu ,2006; Ararat, 2008). Philanthropy practices in Turkey started during Ottoman Empire period. In the Ottoman, the concept of "waqf" or foundation was the institutional basis for the public services. Many services particularly education and health funded, organized, built and maintained through this foundation system. During the Ottoman Empire, schools, universities, libraries, hospitals, soup kitchens, roads, bridges, ports, fountains and other many services have been provided by foundations (Çizakça, 2006; Singer, 2008). In this sense, the social expectation from the firms was shaped the historical foundation philosophy and social responsibility was perceived equivalent to the firms' philanthropic activities (Bikmen, 2003). Therefore, some richest families in Turkey established their family foundations to institutionalize their corporate social responsibility activities.

A review of the extending literature on corporate social responsibility (CSR) provides various definitions of the concept (Bowen, 1953; Carroll, 1979, 1991; Snider et al.,2003; McWilliams et al.,2006). Bowen who introduced first-time corporate responsibility described social responsibilities of businessmen as "the obligations to pursue those policies, to make those decisions, or to follow those lines of action which are desirable in terms of the aims and values of the society (Bowen, 1953, p.6). McWilliams et al. 
(2006, p.1) described CSR as "situations where the firm goes beyond compliance and engages in 'actions that appear to further some social good, beyond the interest of the firm and that which is required by law'".

A well-known and most widely accepted conceptualization of CSR is Carroll's pyramid of CSR. Carroll's four dimensions of CSR refer to the total responsibilities of a company. Economic responsibilities are fundamental responsibilities of companies and are placed at the base. Economic responsibilities refer to the production of services and goods and the selling them with profit. Legal responsibilities refer to fulfilling the economic responsibilities within legal responsibility. Companies obey the law in their all operations. Ethical responsibilities comprise those activities that are expected by the society although they are not necessarily established by legal system. Companies are responsible for being good that goes beyond complying with the law or the level of acceptable behavior. Companies operate in ethical responsibilities to be regarded as good corporate citizens. Philanthropic (discretionary) responsibilities are "those about which society has no clear-cut message for business" (Carroll, 1979, p. 500).

This study is a qualitative study based on the data collected through website of the corporate (sponsored) foundations. The sample of family businesses in Turkish for this investigation is gathered from "100 Richest People of Turkey in 2020" list published by the Forbes magazine. Firstly, the websites of holdings or business groups were investigated and the corporate foundations of Richest Families were examined and, secondly, the founding years and fields of activity of corporate foundations are also revealed. After investigation via internet websites, 22 corporate foundations are listed.

According to findings, big majority of the corporate foundations has been founded in last thirty years. The first family foundation is Vehbi Koç Foundation which was established in 1969. The other foundations began to emerge in the period after 1970, which saw a rapid growth in the 1990s and it is understood that continued its development in the 2000s.

The results of this study show that many of the corporate foundations emphasize on the similar activities. Many foundations carry out corporate social responsibility activities in the field of education, culture-art, and other social issues. On the other hand, some family foundations concentrate 
their attention on the specific field such as health and environment. Some examples for the fields from the websites of the family foundations were provided.

Since the study employed "Turkey's 100 Richest Family" list by Forbes magazine, this could cause to ignore some corporate foundations. There are no studies regarding corporate foundations in Turkey and their philantrophic activities in literature in details and therefore this study creates a base for further studies. Further studies that will build on this study can focus more deeply on corporate foundations and corporate philanthropy perspectives and conduct research on selecting good recipients, attracting funders, improving the performance of recipients, and advancing knowledge and practice in the field.

\section{Kaynakça / References}

Aktan Çoşkun, C. (2007). Kurumsal sosyal sorumluluk. İstanbul: İGİAD Yayınları.

Aydın, D. (2006). Cumhuriyet dönemi vakıfları: Tarihi bir bakış ve vergi muafiyetine sahip vakıfların mali krizi. R. Zincir ve F. Bikmen (Der.), Türkiye'de hayırseverlik: Vatandaşlar, vakıflar ve sosyal adalet. İstanbul: TÜSEV, 21-31.

Bowen, H. R. (1953). Social responsibilities of the businessman. Harper and Row, New York.

Carroll, A. B. (1979). A three-dimensional conceptual model of corporate performance. Academy of Management Review, 4(4), 497-505.

Carroll, A. B. (1991). The pyramid of corporate social responsibility: Toward the moral management of organizational stakeholders. Business Horizons, July-August, 39-48.

Carroll, A. B. (1999). Corporate social responsibility: Evolution of a definitional concept. Business ESociety, 38(3), 268-295.

Çizakça, M. (2006). Osmanlı dönemi vakıflarının tarihsel ve ekonomik boyutları. R. Zincir ve F. Bikmen (Der.). Türkiye'de Hayırseverlik: Vatandaşlar, Vakıflar ve Sosyal Adalet. İstanbul: TÜSEV, 21-31.

Friedman, M. (1962). Capitalism and freedom, University of Chicago Press, Chicago.

Gelir İdaresi Başkanlığı. (2021). Veri muafiyeti tanınan vakıfların listesi. Erişim Tarihi: 01.05.2021. https://www.gib.gov.tr/yardim-ve-kaynaklar/yararli-bilgiler/vergi muafiyeti-taninan-vakiflarin-listesi. 
Komisyonu, A. B. (2001). Green paper: Promoting a European framework for corporate social responsibility. Commission of the European Communities, Brüksel.

Hill, R. P. (1994). Bill collectors and consumers: A troublesome exchange relationship. Journal of Public Policy \& Marketing 13(1), 20-35.

Marx, J.D. (1999). Corporate philanthropy: What is the strategy?. Nonprofit and Voluntary Sector Quarterly, 28(2), 185-198.

McAlister, D.T. and Ferrell, L. (2002). The role of strategic philanthropy in marketing strategy. European Journal of Marketing, 36, 689-705.

McWilliams, A. and Siegel, D. S. (2001). Corporate social responsibility: A theory of the firm perspective. Academy of Management Review, 26, 117127.

McWilliams, A., Siegel, D. S. and Wright, P. M. (2006). Corporate social responsibility: Strategic implications. Journal of Management Studies, 43(1), 1-18.

Mohr, L. A., Webb, D. J. and Harris, E. (2001). Do consumers expect companies to be socially responsible? The impact of corporate social responsibility on buying behavior. The Journal of Consumer Affaires, 35(1), 45-71.

Porter, M.E. and Kramer, M.R. (2002). The competitive advantage of corporate philanthropy. Harward Business Review, December, 57-68.

Sağlam, M. F. (2020). Forbes Türkiye en zengin 100 Türk listesi (2020). Erişim Tarihi: 01.04.2020. https://www.brandingturkiye.com/forbes-turkiye-enzengin-100-turk-listesi-2020/.

Simon, F.L. (1995). Global corporate philanthropy: A strategic framework, International Marketing Review, 12(4), 20-37.

Snider, J, Hill, R.P. and Martin, D. (2003). Corporate social responsibility in the 21st Century: A view from the world's most successful firms. Journal of Business Ethics, 48, 175-187.

\section{Kaynakça Bilgisi / Citation Information}

Yıldız, Ü. (2021). Şirket vakıfları: En zengin 100 Türk listesi üzerine keşifsel bir çalışma. OPUS-Uluslararası Toplum Araştırmaları Dergisi, 18(41), 3825-3839. DOI: 10.26466/opus.950607. 